\title{
Standardization and Optimization of Initiation, Shooting and Rooting Medium for Patchouli Micro-Propagation
}

\author{
Dindayal Darunde', Swapnil Pandey² \\ ${ }^{1}$ Scholar, ${ }^{2}$ Assistant Professor \\ ${ }^{1}$ Adithya Biotech Lab and Research Private Limited, Raipur, India \\ 2Varanasi College of Pharmacy, Babatpur, Varanasi, Uttar Pradesh, India
}

\begin{abstract}
How to cite this paper: Dindayal Darunde | Swapnil Pandey "Standardization and Optimization of Initiation, Shooting and Rooting Medium for Patchouli MicroPropagation" Published in International Journal of Trend in Scientific Research and Development (ijtsrd), ISSN: 24566470, Volume-3 | Issue-3, April 2019, pp.895-902, URL: https://www.ijtsrd.c om/papers/ijtsrd23 033.pdf

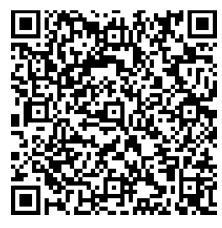

IITSRD23033
\end{abstract}

Copyright (C) 2019 by author(s) and International Journal of Trend in Scientific Research and Development Journal. This is an Open Access article distributed under the terms of the Creative Commons

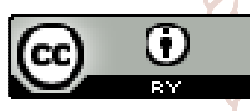
Attribution License (CC BY 4.0) (http://creativecommons.org/licenses/ by/4.0)

\section{ABSTRACT}

The media and hormone composition has been standardization and optimization from petiolate explants of Pogostemon Cablin Benth. a medicinally important plant species belonging to the family Lamiaceae. Axillary shoot bud proliferation was initiated from nodel explants cultured on Full MS, $1 / 2$ MS and $3 / 4$ MS medium supplemented with various concentrations of 6 Benzylaminopurine (BAP), Indol-3-acetic acid (IAA) in mg/l. The small shoot started appearing with in 7 to 10 days in all cultured bottles, growth was found in Full MS + 0.6 mg/lit BAP + $0.12 \mathrm{mg} / \mathrm{lit}$ IAA. For Shoot Multiplication, MS supplemented with Full MS + 1.5 $\mathrm{ml} /$ lit BAP + $0.3 \mathrm{ml}$ IAA after 30 days of incubation the average shoot length recorded in the medium was found to be $1.79 \mathrm{~cm}$ and 1.19 respectively. And For Root Induction Full MS, $1 / 2$ MS, and 3/4 MS supplemented medium with three different concentration of IAA and IBA was used the frequency of root formation response was different in all media, best root formation response was obtained in rooting media AR-I having concentration Full MS $+0.5 \mathrm{ml} / \mathrm{lit} \mathrm{IAA}+1 \mathrm{ml} / \mathrm{lit}$ IBA average no of plant showing root formation were 3.5 in rooting media. About 24 rooted plantlets were selected for transfer in primary hardening. This ex agar plant was transferred to green house for optimizing the physiological condition. Plant were planted in pro trays containing coco peat was found to be suitable for plant growth. At the same time some of physiological parameters were optimized. Pogostemon Cablin plantlets when grow polythene sheet tunnel show best results where about 50 to $70 \%$ of relative humidity and $280 \mathrm{C}$ temperature was maintained. It was also observed that plants were efficiently acclimatized after 30 days of incubation under polythene tunnels. The plants were well habituated in primary hardening condition and 8 plants could not survive in green house indicating very low morality rate in Pogostemon Cablin.

\section{KEYWORDS: Pogostemon Cablin Micro-propagation}

\section{INTRODUCTION}

Patchouli (Pogostemoncablin Benth) belonging to the family Lamiaceae, is a perennial, branched, aromatic herb with fragrant leaves. The patchouli plant was first described by botanist Pelletier-Sautelet in Philippines in 1845 and was named Pogostemonpatchouli. It is believed to be a native of the Philippines. It grows wild in several parts of the world. It grows wild in Malaysia, Indonesia and Singapore as well. Patchouli was introduced to India during the year 1941 in Madhya Pradesh, Tamil Nadu, Kerala and Karnataka. In India, it is cultivated in coastal areas of South India, West Bengal, Assam, Karnataka, Madhya Pradesh and coastal regions of Gujarat. Commercial cultivation of this crop in India was first attempted by Tata Oil Mills in 1942. After the initial stray attempts to grow the crop, its systematic cultivation started in 1962 by CIMAP (Kumar et al., 1986).

The commercial oil from patchouli is extensively used in perfumes and cosmetics (Hasegawa et al., 1992, Maheswari et al., 1993). The oil is widely used in the manufacture of soaps, scents, body lotions and detergents. It is been used to treat dysentery, diarrhea, colds without fevers, vomiting and nausea. The essential oil may be used to treat acne, dry skin, fungal infections, dermatitis, dandruff and eczema (Kalra et al., 2006). The fresh leaves can help in healing burns. In aromatherapy, it is used to calm nerves, control appetite, and relieves depression, stress and lack of sexual interest (Bowel et al., 2002). It also possesses insecticidal, antibacterial and antifungal properties (Kukreja et al., 1990, Yang, 1996, Pattnaik et al., 1996). Fibrinolytic and anti thrombotic activity of this essential oil is also been reported (Sumi, 2003, Eunkyung et al., 2002). This is mostly in the form of cosmetics, perfume, soft drink and food. Therapeutically these are used as antiseptic, stimulant, carminative, diuretic, antihelmintic, analgesics, anti-rheumatic and counter irritant (Rao et al., 2002).

Patchouli is usually propagated by stem cuttings. Meristemtip culture for mass production of patchouli was successfully carried out which resulted in pathogen free plantlets for cultivation in the fields and results were 
promising with significant increases in leaf biomass and essential oil yield. Clonal propagation and shoot meristem culture were also reported in patchouli. Volkhovskaya (1968) first reported rooting of patchouli leaves and subsequent development of shoots. Selvarajan and Madhava Rao (1981) reported only rooting but no shoot formation. Vasantha Kumar and Narguda (1987) reported shoot formation in leaf cuttings but subsequent growth was slow and took 80-140 days for plantlet to reach optimum size suitable for transplanting. Further, leaf with a portion of petiole was used and shoot development occurred after callus formation in the cut end of petiole. This resulted in delayed shoot initiation and low success in plantlet production.

The essential oils are usually complex mixture of terpenes and their oxygenated derivatives. The essential oils are practically insoluble in water, generally lighter than water, and possess characteristic odour. But most cases evidence for plant regeneration was restricted to only very few explant types. There are also some reports on callus induction and plant regeneration in patchouli (Mihsra, 1996; Santos et al., 2011).some of this method gave a lot of little shoots, but these might need for more time period to develop plantlets. Hence, there is certainly a need for more research to meet commercial-scale vegetative propagation of patchouli. In the present study, the comparison of shoot induction ability of different explants (leaf, nodal stem, petiole, intermodal stem segment and root tip) was conducted, and the effect of plant growth regulators (PGRs) on shoot and root induction were studied. The study was to establish a high frequency and rapid regeneration protocol for patchouli.

\section{Review of Literature}

Patchouli plant was first described by Pelletier-Sautelet in 1845 and he was named as Pogostemon patchouli. In 1896, Holmes identified it as P. cablin. The word cablin is derived from 'cabalam' which is also a local name for the Patchouli in the Philippines and these are synonymous (Bhaskar and Vasantha Kumar, 2000). About 25 species of Pogostemon are reported to occur in India. Patchouli is also known as patchouly, tamalapatrain Sanskrit, patcholiin Hindi, patchetenein Kannada, pacchilaiin Tamil, patchillain Malayalam, patchapanor patchain Marathi and guanghouxiangin Chinese.

The essential oil is used to treat acne, dry skin, fungal infections, dermatitis, dandruff and eczema (Kalraet al., 2006). The fresh leaves can be help in healing burns. In aromatherapy, it is used to calm nerves, control appetite, relieves depression, stress and lack of sexual interest (Bowel et al., 2002). It has insecticidal, antibacterial and antifungal properties (Kukreja et al., 1990, Yang, 1996, Pattnaik et al., 1996).

Fibrinolytic and anti thrombotic activity of this essential oil is also been reported (Sumi, 2003, Eunkyung et al., 2002).This is mostly used in the form of cosmetics, perfume, soft drink and food. Therapeutically it is used as antiseptic, stimulant, carminative, diuretic, antihelmintic, analgesics, anti-rheumatic and counter irritant (Rao et al., 2002).

\section{Origin, wild relatives and distribution}

Patchouli, a native of the Philippines, growing wild in many South Asian countries is presently cultivated on a commercial scale in India, Indonesia, Malaysia, China and
Singapore. Commercial cultivation of this crop in India was first attempted by Tata Oil Mills in 1942. After initial stray attempt to grow the crop, its systematic cultivation was started in 1962 by CIMAP at its Regional Centre in Bangalore (Anup Kumar et al., 1986). Subsequently, Patchouli has been cultivated in some parts of India. Patchouli can be cultivated in coastal regions of India as a main crop or as an intercrop along with plantation crops. Patchouli, being a shade loving plant can be easily grown as an intercrop amidst fruit trees, arecanut and coconut plantations. It can also be easily cultivated in flood free fallow. Patchouli is a hardy perennial herb adapted to hot and humid climatic conditions and found in South East Asia (Maheshwariet al., 1993).

Several varieties of Patchouli, both wild and cultivated whose leaves and buds yield oils with Patchouli- like odour are found growing in India, particularly in Western Ghats, districts of Malabar, South Canara, Maharashtra, Madhya Pradesh, Assam and West Bengal, where climatic conditions are similar to those of Malaya and Sumatra (Menon, 1960). $P$. heyneaus (Syn. P. Fleurissant Benth.) is indigenous to Indiaand is cultivated in Java under the name 'dilem'. In commerce, it is popular as Javanese Patchouli or Dilem herb. It resembles $P$. paniculatus growing near Malabar, Deccan and Mumbai (Menon, 1960). P. plentranthoides Desf (Syn. P. benghalensis) grows in Taraiand Bhadar forest division of Uttar Pradesh. It is a large shrub growing mostly in shady and moist places. Spikes are more than leaves and contain more oil. It flowers profusely and the plant yields $0.25 \%$ oil (Thapaet al., 1971).

\section{Micropopagation}

Micro-propagation (or in vitro propagation) is the most common term this term used for clonal, true-to type propagation of plants by variety of tissue, cell or organ culture methods. Its implies of aseptic culture small sections (explants) of tissue and organs, in closed vessels with defined culture media and under controlled environment condition micro propagation, in addition to genetic engineering, is at present the most commercially efficient and practically oriented plant biotechnology resulting in rapid generation of large number of clonal plants.

\section{Advantages of micro-propagation:-}

Micro-propagation has a number of advantages over traditional plants propagation techniques:

$>$ The main advantage of micro-propagation is the production of many plants that are clones of each other.

$>$ Micro-propagation can be used to produce disease free plants.

$>$ It is only viable method of regenerating genetically modified cells or cells after protoplast fusion.

$>$ Rapid multiplication of genetically uniform plants that posse's desirable trait. Single explants can be multiplied into many thousand plants in a very short time.

$>$ The production of multiplies of plants in the absence of seeds or necessary pollinators to produce seeds.

$>$ The production of plants in sterile containers that allows them to be moved with greatly reduced chances of transmitting diseases, pests and pathogens.

\section{Disadvantages of micro-propagation:}

Micro-propagation is not always means of multiplying plants. Conditions and limits are including:

$>$ It is very expensive, and can have a labour cost of more than $70 \%$. 
$>$ A monoculture is produced after micro-propagation, leading to lack of overall disease resistance, as all progeny plants may be vulnerable to the same infections.

$>$ An infected plant sample can produce infected progeny.

$>$ Not all plants can be successfully tissue cultured, often because proper medium for growth is not known or the plant produce secondary metabolic chemicals that stunt or kill the explants.

$>$ Sometimes plants or cultivars do not come true to type after being tissue cultured. This is often dependent on the type of explants material utilized during the initiation phase or result of the cell or propagates line.

$>$ Some plants are very difficult to disinfect of fungal organisms.

\section{Media Components}

Murashige and Skoog (1962) medium supplemented with different phyto-hormones as per treatments were used as culture medium for shoot induction, shoot multiplication and maintenance and regeneration of roots from multiplied shoot. Hormones were added separately to different media according to the requirements. For the preparation of media, stock solutions were prepared at the beginning and stored at $4^{\circ} \mathrm{C}$ temperature. The respective medium was prepared from the stock solutions. And vitamins are also prepared and stored in $4^{\circ} \mathrm{C}$ temperature. The conventional MS macronutrients were used as a 3/4. Add BAP 100 . The $\mathrm{pH}$ of all the media was adjusted to 5.8 before adding gelling agent agar. The media were sterilized at the temperature of $121^{\circ} \mathrm{C}$ for 20 minutes. After autoclaving, the culture medium is stored in clean dust free chamber for 1-2 days before use in order to check for any contamination. Bacterial contamination may be observed, particularly during rainy days. Use of ampicillin in the initiation and subsequent cultures helps to prevent the latent bacterial contamination.

\section{Growth Regulators}

Some chemicals occurring naturally within plant tissues (i.e., endogenously) have a regulatory rather than a nutritional role in growth and development. These compounds, which are generally active at very low concentrations, are known as plant hormones (or plant growth substances). We have already considered of plasticity and totipotency. The essential point as far as plant tissue culture is considered is that, due to this plasticity and totipotency, specific media manipulations can be used to direct development of plant cells in culture. Plant growth regulators are the critical media components in determining the developmental pathway of the plant cells. The plant growth regulators used most commonly are plant hormones or their synthetic analogues.

There are two main classes of plant growth regulator used in plant cell culture; Auxins and cytokinins are by far the most important plant growth substances for regulating growth and morphogenesis in plant tissue and organ cultures; in these classes, synthetic regulators have been discovered with a biological activity, which equals or exceeds that of the equivalent natural growth substances

Auxins:-

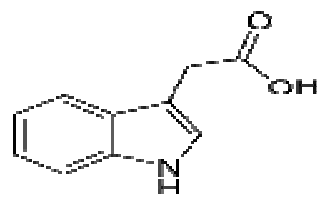

Auxins promote both cell division and cell growth the most important naturally occurring is IAA (indole -3-acetic acid), but its use in plant cell culture media is limited because it is unstable to both heat and light. Occasionally amino acid conjugates of IAA, which are more stable, are used to partially alleviate the problems associated with the use of IAA. It is more common, though, to use stable chemical analogues of IAA as a source auxin in plant cell culture media. 2,4-Dichlorophenoxyacetic acid (2,4-D) is the most commonly used auxin and is extremely effective in most circumstances. $\alpha$-naphthalene acetic acid (NAA), and indole3-butyric acid (IBA) are commonly used in the tissue cultures. Indeed, all active auxins are weak organic acids. The relative degree of activity of individual auxins in different growth processes is very variable. It differs not only from plant to plant but also from organ to organ, tissue to tissue, cell to cell, and also with the age and physiological state of the plant.

Cytokinins:-

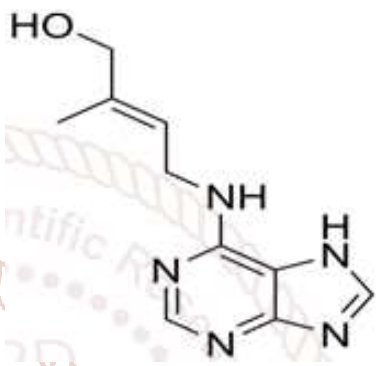

Cytokinins promote cell division. Naturally occurring cytokinins are a large group of structurally related compounds. Of the naturally occurring cytokinins, two have some use in plant tissue culture media. These are zeatin and 2ip(2-isopentyl adenine). Their use is not widespread as they are expensive and relatively unstable. The synthetic analogues, kinetin and BAP (benzylaminopurine), are therefore used more frequently. Non-purine-based chemicals, such as substituted phenylureas, are also used as cytokinins in plant cell culture media. These substituted phenylureas can also substitute for auxn in some culture systems.

Cytokinins are N6-substituted adenines with growth regulatory activity in plants that promote cell division and may play a role in cell differentiation. Cytokinins added to the medium are very important during tissue culture of plants because they induce division and organogenesis and affect other physiological and developmental processes.

The success of a culture is affected by the type and concentration of applied cytokinins, because their uptake, transport, and metabolism differ between varieties and they can interact with endogenous cytokinins of an explants. The correlation of auxins and cytokinins in the plants is a constant $(\mathrm{A} / \mathrm{C}=$ const. $)$.

\section{OBJECTIVES OF THIS STUDY}

1. To standardization the media and hormone composition for initiation of patchouli.

2. To development a suitable and reproducible protocol of patchouli shooting and rooting.

\section{PLAN OF WORK}

1. Literature survey.

2. Selection of plant and species and explants for micro propagation. 
3. Standardization of media containing growth hormone.

4. Optimization and development of sterile condition for media.

5. Development protocol and development of media.

6. Standardization of micro propagation.

7. Observations.

\section{MATERIALS AND METHODS}

\section{Plant Materials}

Nodal segments were procured from elite mother plants, maintained at the mother plant nursery of Adithya Biotech Lab and Research Pvt. Ltd., Raipur. All expanded leaves and petioles were removed and the explants were cut into 1 - 2 $\mathrm{cm}$ length. The explants were washed 3 - 4 times in the tap water and treated with liquid soap, teepol for $15 \mathrm{~min}$ followed by thorough washing under tap water. These were then surface sterilized with $0.5 \% \mathrm{HgCl} 2$ for 10 min rinsing was done five times with sterile distilled water to remove traces of $\mathrm{HgCl} 2$ completely. Under aseptic conditions, explants were inoculated on MS (Murashige and Skoog, 1962) medium, containing $2 \%(\mathrm{w} / \mathrm{v})$ sucrose, supplemented with different concentrations and combinations of BA $(0.25$, $0.5,1.0$ and $2.0 \mathrm{mg} / \mathrm{L}$ ) proliferation and multiplication. The $\mathrm{pH}$ of the medium was adjusted to 5.8 prior to the addition of $0.8 \%$ agar and autoclaved at $121^{\circ} \mathrm{C}, 15 \mathrm{lb}$ pressure for 15 min.

\section{Material \\ $>$ MS medium \\ $>$ Sodium hypochloride \\ $>$ Bovistin \& antibiotic \\ $>\mathrm{Hgcl} 2$ \\ $>$ Distil water \\ $>$ Blade}

\section{METHODS}

\section{Methods}

Micro-propagation is usually described as having the following four distinct stages (a stage " 0 " is added by some authors):

1. Stage "0": preparation of in situ donor material (fungicide and/or plant growth regulator)

2. Stage "I": initiation (including surface sterilization) of explants

3. Stage "II": shoot multiplication (optimization of proliferation media)

4. Stage "III": root induction on micro-cuttings (in vitro or ex vitro)

5. Stage "IV": acclimatization of rooted shoots (or unrooted micro-cuttings)

\section{Stage " 0 ": preparation of in situ donor material} (fungicide and/or plant growth regulator)

Fresh Nodal segments of patchouli were collected from the orchard grown plants located in the field of Aditya Biotech Lab and Research Pvt. Ltd., Raipur.

\section{Selection of mother plant}

$>$ Mother plant should be healthy, true to type and free from diseases and pests, especially virus disease.

$>$ The male flower buds should be retained to check the presence of virus diseases.

$>$ Mother plant should be raised under roofless insect proof shade net with sufficient height.

$>$ Pedigree record and source of each mother plant should maintain and catalogued.

\section{Stage "I": initiation (including surface sterilization) of explants}

Shoot cultures of patchouli start conventionally from any part of plant that contains a shoot meristem, pseudo-stem, small suckers, peepers and lateral buds. The apex of inflorescence and auxiliary flower buds are also suitable explants for tissue culture initiation.

For rapid in vitro multiplication of patchouli shoot tips from young of 40-100 cm height are most commonly used as explants. From the selected sucker a cube of tissue about 1-2 $\mathrm{cm}$ containing the apical meristem is excised. The tissue is dipped in $70 \%$ ethanol for 10 sec surface sterilization in a $2 \%$ sodium hypocloride solution, and after second cutting the sucker was dipped into the solution of $1 \%$ bovistin and antibiotic [Ampicillin $(500 \mathrm{mg})]$ for 20 mints. And then the sucker was washed two times in sterile distilled water, and then dipped in the solution of $0.5 \% \mathrm{hgcl} 2$ for 1 hour. And after 1 hour rinsed three times for $10 \mathrm{~min}$ in sterile water. It is all the differ in explants type and size, disinfection procedure, type of disinfectant and its concentration and treatment duration. Subsequently shoot tip of about 3 to $5 \mathrm{~mm}$, consisting of the apical dome covered with several leaf primordial and thin layer of corm tissue, is aseptically dissected.

The optimal size of the explants depends on the purpose. For rapid multiplication, relatively larger explants are desirable despite its higher susceptibility to blackening and contamination. When virus or bacteria elimination is needed, meristem tip culture is the preferred option. The explant is then further reduced in size $(0.5-1 \mathrm{~mm}$ length), leaving a meristematic dome with one or two leaf initials. Meristem cultures have the disadvantage that they may have a higher mortality rate and an initial slower growth.

The explant is placed directly on a multiplication-inducing culture medium. For patchouli micro-propagation, MS-based media are widely adopted. Generally, they are supplemented with sucrose as a carbon source at a concentration of 30-40 $\mathrm{g} / \mathrm{l}$. Patchouli tissue cultures often suffer from excessive blackening caused by oxidation of poly-phenol compounds released from wounded tissues.

Therefore, during the first 4-6 weeks, fresh shoot-tips are transferred to new medium every 1-2 weeks. Alternatively, freshly initiated cultures can be kept in complete darkness for one week. Antioxidants, such as ascorbic acid or citric acid in concentrations ranging from $10-150 \mathrm{mg} / \mathrm{l}$, are added to the growth medium to reduce blackening, or the explants are dipped in antioxidant solution prior to their transfer to culture medium.

Usually two types of growth regulators, a cytokines and an auxin, are added to the patchouli growth medium. Their concentration and ratio determines the growth and morphogenesis of the patchouli tissue.

In most patchouli micro-propagation systems, semi-solid media are used. As a gelling agent agar is frequently added to the culture medium but our preference is for Gel rite because of its higher transparency, allowing much earlier detection of microbial contamination.

Patchouli shoot-tip cultures are incubated at an optimal growth temperature of $28 \pm 2^{\circ} \mathrm{C}$ in a light cycle of $12-16 \mathrm{~h}$ with a photosynthetic photon flux (PPF). 


\section{Stage "II": shoot multiplication (optimization of proliferation media)}

From the same culture, initiated shoots of uniform size, were sub cultured into MS media. One explant was cultured in each bottle, and take that explants and multiplication of the shoots from the many steps. Shoots were sub culturing in 5 steps after 25 days. After 25 day the number of shoots produced per explants.

The formation of multiple shoots and buds is promoted by supplementing the medium with relatively high concentrations of cytokines. For the multiplication of propagules, we use the same medium as for the initiation of shoot cultures (different concentrations of medium is containing 1, 2, 3, 4mg/l BAP, $1 \mathrm{mg} / \mathrm{l}$ IAA and .4mg/l ADS). If the production of highly proliferating meristem cultures is required, higher concentration of BAP is added to the culture medium. Higher concentrations of the cytokine BAP tend to have an adverse effect on the multiplication rate and morphology of the culture and should therefore be avoided.

The rate of multiplication depends both on the cytokines concentration and the genotype. In general, shoot tips of cultivars having only A genomes produce 2-4 new shoots, whereas cultivars having one or two B genomes produce a cluster of many shoots and buds at each subculture cycle. Approximately 25-30 days after culture initiation, depending on the initial explant size, new auxiliary and adventitious shoots may arise directly from the shoot-tip explants.

\section{Stage "III": root induction on micro-cuttings (in vitro or ex vitro)}

Individual shoot or shoot clumps are transferred to a nutrient medium which does not promote further shoot proliferation but stimulates root formation. The cytokine in the regeneration medium is greatly reduced or even completely omitted. Within 2 weeks, shoot tips develop into unrooted shoots. To initiate rhizogenesis NAA (anaphthalene acetic acid) or IBA (indole-3-butyric acid) are commonly included in the medium at between $0.25,1.0$ and $2 \mathrm{mg} / \mathrm{l}$. We use the same auxin concentration as in the proliferation medium for IAA and IBA. For some genotypes of patchouli that produce compact proliferating masses of buds, activated charcoal $(0.1-0.250 \%)$ is added to the regeneration/rooting medium to enhance shoot elongation and rooting. After rooting, plants are hardened in vitro for some extra day's incubation on the regeneration/rooting medium prior to transplantation to soil.

\section{Stage "IV": acclimatization of rooted shoots (or un- rooted micro-cuttings)}

The in vitro regenerated plantlets with well-developed shoot root and leaf systems were ready to shifting outside of the laboratory. They are carefully acclimatised to adapt green house and later to least protected field conditions. During hardening the plantlets undergo physiological adaptation to changing external factors like water, temperature, relative humidity and nutrient supply. The plantlets from culture vessels/bottles are moved from the laboratory. They are shifted to green house for primary hardening.

\section{RESULT AND DISCUSSTION}

The tissue culture was done through explants as auxiliary bud after 1 month of initiation newly shoot had been generated. Shoot had be re-cultured and transferred to multimedia, thereby transferred to green house.

\section{Initiation of Explants}

Auxiliary buds from mother plant were used as explants for in vitro regeneration the explants cutted into desired shape and size with different concentration of BAP and IAA for initiation and establishment small shoot started appearing with in 7 to 10 days in all cultured bottles, growth was found in Full MS + $0.6 \mathrm{mg} / \mathrm{lit}$ BAP $+0.12 \mathrm{mg} / \mathrm{lit}$ IAA. The observation and result obtained in the study and discuss in this section.

\begin{tabular}{|c|c|c|c|}
\hline $\begin{array}{c}\text { Media } \\
\text { type }\end{array}$ & $\begin{array}{c}\text { Media } \\
\text { composition }\end{array}$ & $\begin{array}{c}\text { Initial } \\
\text { height of } \\
\text { explants } \\
\text { (avg) }\end{array}$ & $\begin{array}{c}\text { No of } \\
\text { leaves } \\
\text { after 7 } \\
\text { days (avg) }\end{array}$ \\
\hline AI-I & $\begin{array}{c}\text { Full MS + 0.6 } \\
\text { ml/lit BAP + } \\
0.12 \mathrm{ml} / \mathrm{lit} \text { IAA }\end{array}$ & 1.3 & 4 \\
\hline AI-II & $\begin{array}{c}1 / 2 \mathrm{MS}+0.3 \\
\mathrm{ml} / \mathrm{lit} \text { BAP + } \\
0.6 \mathrm{ml} / \mathrm{lit} \text { IAA }\end{array}$ & 1.5 & 2 \\
\hline AI-III & $\begin{array}{c}3 / 4 \mathrm{MS}+0.2 \\
\mathrm{ml} / \mathrm{lit} \text { BAP + } \\
0.4 \mathrm{ml} / \mathrm{lit} \text { IAA }\end{array}$ & 1.1 & 1 \\
\hline
\end{tabular}

Table no 1: Effect of different concentration of BAP and IAA in combination for initiation

\section{For Shoot Multiplication}

For recording average no of no of multiple shoot and shoot elongation randomly 10 bottles were selected for periodic observation and documentation through 2 sub cultured of Pogostemon cablin, It was observed in AM-I medium i.e. MS supplemented with Full MS $+1.5 \mathrm{ml} /$ lit BAP $+0.3 \mathrm{ml}$ IAA after 30 days of incubation the average shoot length recorded in the medium was found to be $1.79 \mathrm{~cm}$ and 1.19 respectively. Whereas minimum shoot length of $0.89 \mathrm{~cm}$ was observed in media AM-III supplemented with $3 / 4$ MS + 0.1 $\mathrm{ml} /$ lit $+0.2 \mathrm{ml} / \mathrm{lit}$ IAA. The observation and result obtain ed in the study and discuss in this section.

\begin{tabular}{|c|c|c|c|c|}
\hline $\begin{array}{c}\text { Media } \\
\text { type }\end{array}$ & $\begin{array}{c}\text { Media } \\
\text { composition }\end{array}$ & $\begin{array}{c}\text { (avg) } \\
\text { no of } \\
\text { shoots }\end{array}$ & $\begin{array}{c}\text { (avg) } \\
\text { height of } \\
\text { shoots }\end{array}$ & $\begin{array}{c}\text { (avg)no } \\
\text { leaves }\end{array}$ \\
\hline AM-I & $\begin{array}{c}\text { Full MS + 1.5 } \\
\text { ml/ lit BAP + } \\
0.3 \text { ml IAA }\end{array}$ & 4.2 & 1.79 & 45.2 \\
\hline AM-II & $\begin{array}{c}1 / 2 \text { MS + 0.75 } \\
\text { ml/lit BAP + } \\
0.15 \text { ml IAA }\end{array}$ & 2.4 & 1.19 & 42 \\
\hline AM-III & $\begin{array}{c}3 / 4 \text { MS + 0.1 } \\
\text { ml/ lit + 0.2 } \\
\text { ml/lit IAA }\end{array}$ & 1.4 & 0.89 & 31.4 \\
\hline
\end{tabular}

Table no 2: Effect of different concentration of BAP and IAA in combination in shoot multiplication

\section{Survival Percentage}

The percentage of survival varied between shooting media carrying different levels of BAP. The maximum survival rate was found in the medium containing $1.5 \mathrm{ml} /$ lit BAP and 0.3 ml IAA on which shoot active and healthy were compared to other treatments. The survival percentage found in multiplication of shoot was found to be $65 \%$. It was observed that survival percentage increased with number of sub culturing. 


\section{For Root Induction}

The regenerated shoots were used for root induction in root forming media AR-I, AR-II, AR-III. Full, half, and $3 / 4$ MS supplemented with three different concentration of IAA and IBA was used the frequency of root formation response was different in all media, best root formation response was obtained in rooting media AR-I having concentration Full MS $+0.5 \mathrm{ml} /$ lit IAA $+1 \mathrm{ml} /$ lit IBA average no of plant showing root formation were $3.5 \mathrm{in}$ rooting media where as AR-II and AR-III respectively. The frequency of root formation was recorded best in AR-I heavy healthy roots more than 3 roots per plant and whitish colour. Growth was found in Full MS + $0.5 \mathrm{ml} /$ lit IAA $+1 \mathrm{ml} /$ lit IBA. The observation and result obtained in the study and discuss in this section.

\begin{tabular}{|c|c|c|c|}
\hline $\begin{array}{c}\text { Media } \\
\text { type }\end{array}$ & $\begin{array}{c}\text { Media } \\
\text { composition }\end{array}$ & $\begin{array}{c}\text { No. of plants } \\
\text { showing roots } \\
\text { (mean value) }\end{array}$ & $\begin{array}{c}\text { Avgas } \\
\text { height of } \\
\text { shoots }\end{array}$ \\
\hline AR-I & $\begin{array}{c}\text { Full MS + 0.5 } \\
\text { ml/lit IAA + } \\
\text { ml/lit IBA }\end{array}$ & 3.5 & 2.1 \\
\hline AR-II & $\begin{array}{c}1 / 2 \mathrm{MS}+0.25 \\
\mathrm{ml} / \mathrm{lit} \text { IAA + } \\
0.5 \mathrm{ml} / \mathrm{lit} \text { IBA }\end{array}$ & 2.2 & 1.89 \\
\hline AR-III & $\begin{array}{c}3 / 4 \mathrm{MS}+0.33 \\
\mathrm{ml} / \mathrm{lit} \text { IAA + } \\
0.66 \mathrm{ml} / \mathrm{lit} \text { IBA }\end{array}$ & 1.45 & 0.9 \\
\hline
\end{tabular}

Table no 3: Effect of different concentration of IBA and IAA on Root induction

\section{Hardening}

About 24 rooted plantlets were selected for transfer in primary hardening. This ex agar plant was transferred to green house for optimizing the physiological condition. Plant were planted in pro trays containing coco peat was found to be suitable for plant growth. At the same time some of physiological parameters were optimized. Pogostemon Cablin plantlets when grow polythene sheet tunnel show best results where about 50 to $70 \%$ of relative humidity and $28^{\circ} \mathrm{C}$ temperature was maintained. It was also observed that plants were efficiently acclimatized after 30 days of incubation under polythene tunnels. The plants were well habituated in primary hardening condition and 8 plants could not survive in green house indicating very low morality rate in Pogostemon Cablin.

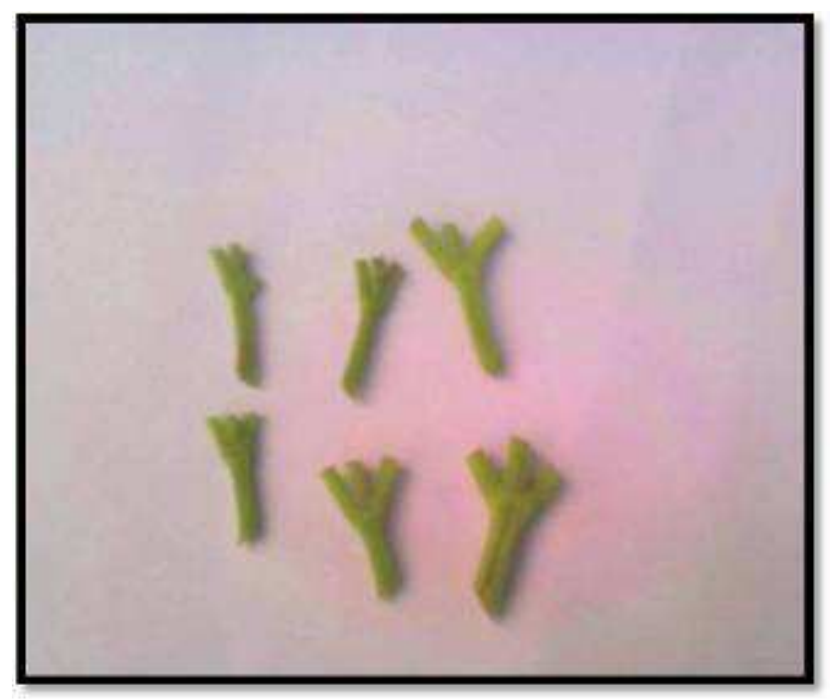

Figure1. Auxiliary bud used as explants

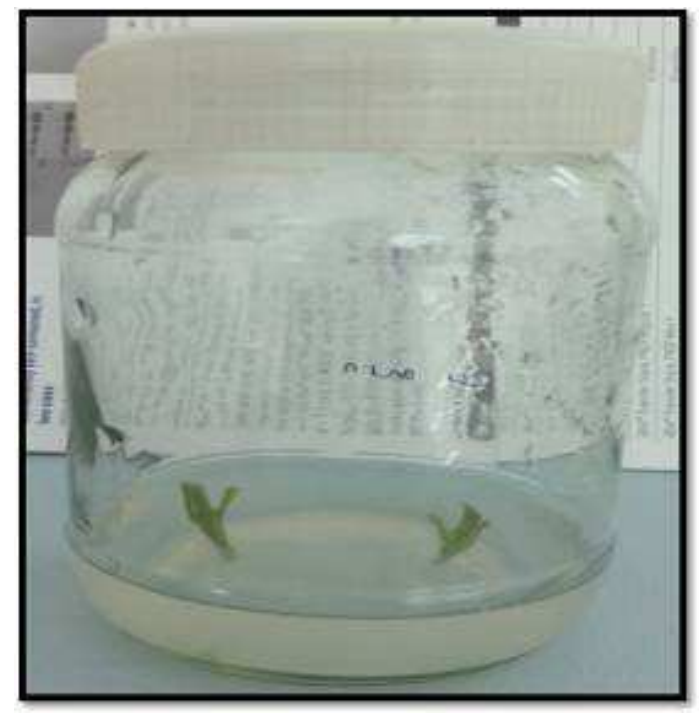

Figure2. Culture initiation of MS media AI-I

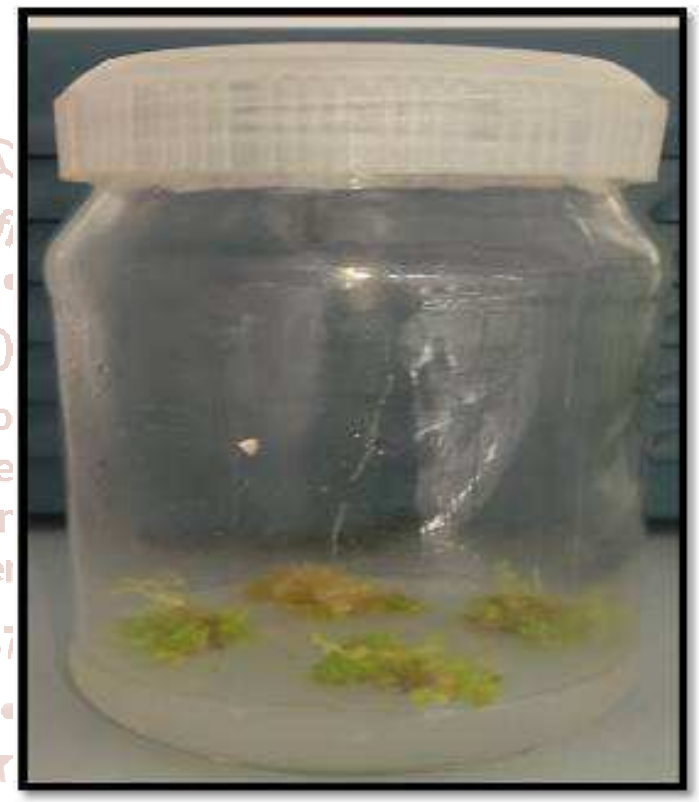

Figure3. Multiplication of shoot in AM-I

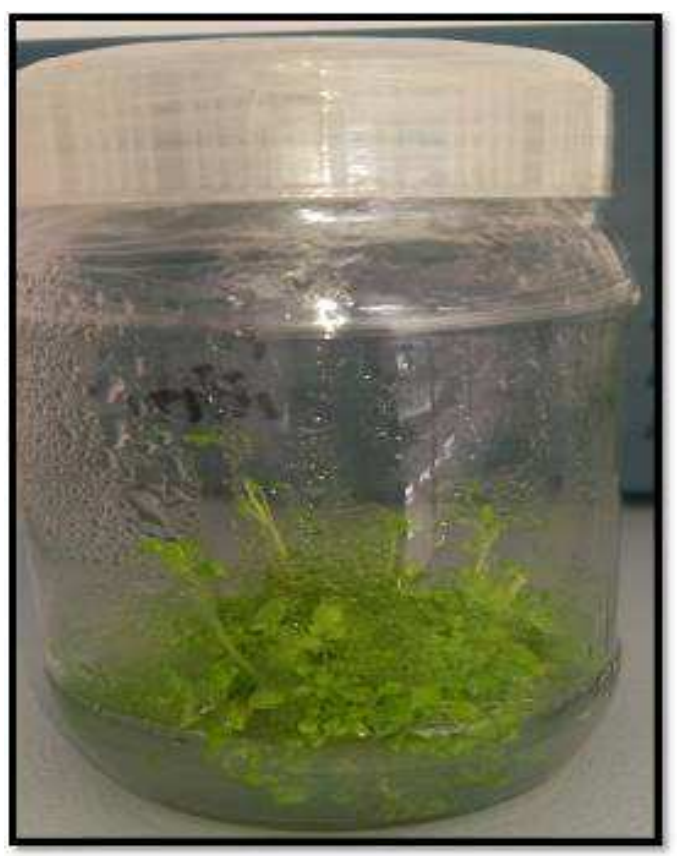

Figure4. Elongation of shoot AM-I 


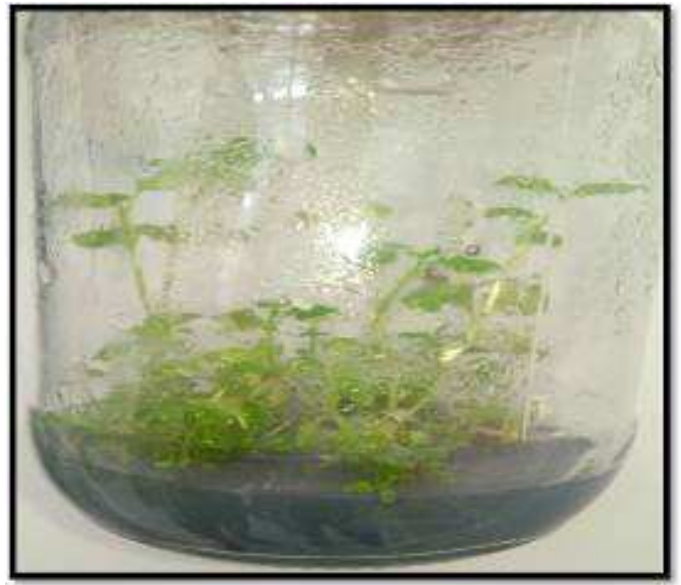

Figure5. Rooting induction media AR-I for elongated shoots

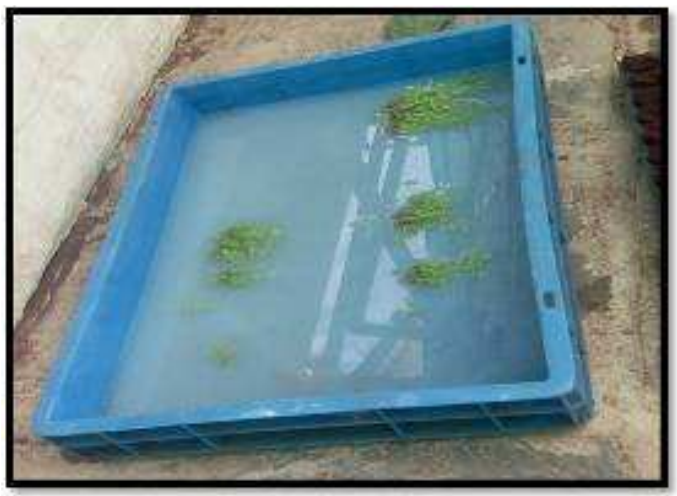

Figure6. During washing of plantlets

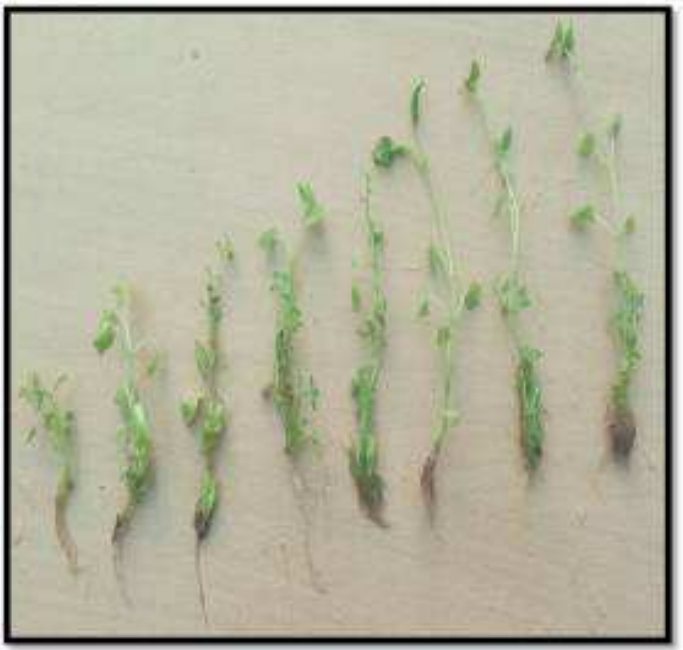

Figure7. After washing of plantlets

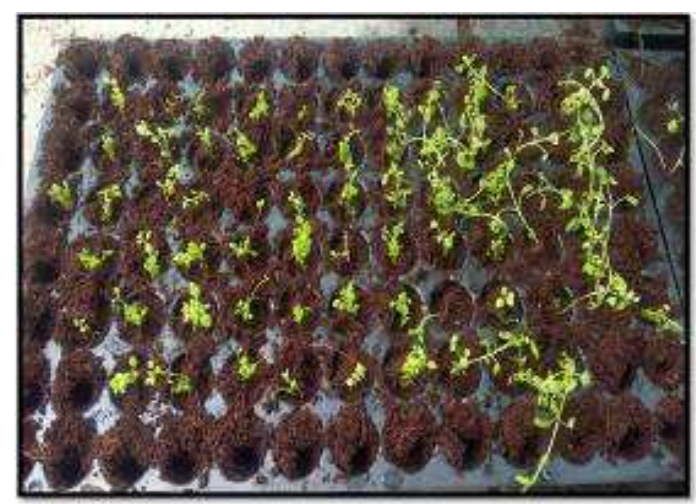

Figure8. Primary hardening of plantlets

\section{CONCLUSION}

The present study was carried out to "Standardization and Optimization of Initiation, Shooting and Rooting medium were the major objective of the study. Media containing BAP Full MS + $0.6 \mathrm{ml} / \mathrm{lit}$ BAP + $0.12 \mathrm{ml} / \mathrm{lit}$ IAA in MS medium was found most suitable for initiation. For shoot proliferation \& multiplication AM-I media i.e. MS supplemented with Full MS $+1.5 \mathrm{ml}$ / lit BAP $+0.3 \mathrm{ml}$ IAA was found to be best while for root induction AR-I i.e. MS supplemented with Full MS + 0.5 $\mathrm{ml} /$ lit IAA $+1 \mathrm{ml} / \mathrm{lit}$ IBA. In rooting stage three different combinations of IAA and IBA in \% strength MS medium were tested and the AR-I media (VS strength MS media supplemented with $0.5 \mathrm{ml} /$ lit IAA and $1 \mathrm{ml} /$ lit IBA) showed optimum root formation and development. From the present study it can be concluded that MS media supplemented with Full MS $+0.6 \mathrm{ml} / \mathrm{lit}$ BAP $+0.12 \mathrm{ml} / \mathrm{lit} \mathrm{IAA}$ is best for initiation. For shoot proliferation \& multiplication strength MS media supplemented with Full MS + $1.5 \mathrm{ml} /$ lit BAP +0.3 ml IAA is best. while root induction strength of MS media supplemented with Full MS + $0.5 \mathrm{ml} / \mathrm{lit}$ IAA $+1 \mathrm{ml} /$ lit IBA .

\section{SUMMARY}

The present study on Standardization and Optimization of Initiation, Shooting and Rooting Medium for patchouli Micropropagation through plant tissue culture- was conducted at Adhitya Biotech Agricon Research and Development Centre, Nandanvan Road Raipur (C.G.). The main objective of plant tissue culture of patchouli was to standardize protocol for initiation, mass multiplication and root induction of Pogostemon Cablin. Healthy explants were taken from the selected elite mother plants from the Pogostemon Cablin field and dipped in the $2 \%$ Sodium hypochloride solution. The explants were excised into optimum shape and size (1.7-2.1) and treated with $1 \%$ bovistin solution for 20 minutes followed by treatment with $0.2 \% \mathrm{HgCL}_{2}$ for 10 minutes.

The initiation of micro-propagation of Pogostemon Cablin encircles media preparation which includes MS medium containing concentration of Full MS $+0.6 \mathrm{ml} / \mathrm{lit} \mathrm{BAP}+0.12$ $\mathrm{ml} /$ lit IAA after inoculation to the media, incubated at $25^{\circ} \mathrm{C}$ and $30 \%$ relative humidity. The culture was incubated for one month and for the multiplication of shoots on the media viz. AM-I, AM-II and AM-III containing BAP and IAA. With depletion of nutrients the inoculums need to be sub-cultured into the fresh media.

After second to third fourth sub- culture, culture was induced for root induction. Regenerated shoots were transferred to the rooting media containing three different combination of IBA, and IAA. Culture was incubated in same conditions as in initiation for 1 month for the rooting of shoots on the media viz.AR-I, AR-II,AR-III Incubation period for rooting was 1 month at $25^{\circ} \mathrm{C}^{0}$ temperature after rooting the plantlets were transferred to primary hardening which was allowed to adapt gradually to the external environment.

\section{Refrences:-}

[1] Bharati N (2002). Biotechnology in commercial production of patchouli in NE region. In : Patchouli. NationalWorkshop on Commercialization of patchouli in NE region dated 9-11 April, 2002 at Guwhati, Assam organized by NEDFC and NHB, pp:46-51.

[2] Bowel EJ, Griffiths DM, Quirk L, Brownriggs A, Croot (2002). Effect of essentials oils and touch on resistance to nursing care procedures and other dementia related 
behaviours in a residential care facility. Int. J. Aromather. 12: 22-29

[3] Hasegwa Y, Tajima K, Toli N, Sugimura Y (1992).An additional constituent occurring in the oil from a patchouli cultivar. Flav. Fragr.J.7:333-335

[4] Kukreja AK, MathurAK, Zaim M (1990). Mass production of virus free patchouli plants [Pogostemoncablin (Blanco) Benth.] by in vitro culture. Trop.Agrc.67: 101-104.

[5] Kumaraswamy M, Balasubramanya S, Anuradha M (2010). Invitro multiplication of PogostemoncablinBenth. Through direct organogenesis. Afr J Biotechnol 9 (14) : 2069-2075

[6] Maheswari , ML, Vasantha Kumar T, Neelam Sharma and Chandel KPS (1993). Patchouli- An Indian perspective. Indian perfumer, 37:9-11.

[7] Meena M (1996). Regeneration of patchouli cablinBenth.)plants from leaf and node callus and evaluation after growth in the field. Plant cell Rep., 15:991-994.

[8] Misra M (1996). Regeneration of Patchouli (PogostemoncablinBenth.) plants from leaf node callus and evaluation after growth in the field. Plant cell Rep. 15:991-994.
[9] Rajan GB, Shakila A, Rajasekaran LR (1997). Mass peopagation of Pogostemon patchouli through somatic embryogenesis. South Indian Hort. 45: 45-49.

[10] Redenbaugh K, Slade P, Viss PR, Fugii JA (1987).Encapsulation of a somatic embryos in synthetic seed coats. Hort. Sci., 22: 803-809.

[11] Sharma D, Naik PS (1998). Sunseeds in potato: an investigation using nutrient encapsulated in vitro nodal segments. Sci. Hortic. 73:179-184.

[12] Straus J (1960). Development of a synthetic medium. Am.J.Bot.,47: 641-646

[13] Sumi H [2003]. Fibrinolysis- accelerating activity of the essential oils and Shochu aroma. Aroma Res. 4 (3): 264-267.

[14] Vijayakumar, K.2004. Patchouli and India A great leap forward. In: National Seminar of prospectus and potentials of Medicinal and aromatic crops, held at Bangalore, 18-19 June 2004, pp.106-107.

[15] Yang D (1996). Michel, Mandinandriamboavonjy, Poitry, Chaumont, Mellet C Antifungal and antibacterial properties in vitro of three patchouli oils from different origins. Acta Botanica. Gallica. 143 91):29-35. 